\title{
DISPERSION EXPERIMENTS IN CENTRAL LONDON The 2007 DAPPLE Project
}

by Curtis R. Wood, Samantha J. Arnold, Ahmed A. Balogun, Janet F. Barlow, Stephen E. Belcher, Rex E. Britter, Hong Cheng, Adrian Dobre, Justin J. N. Lingard,

Damien Martin, Marina K. Neophytou, Fredrik K. Petersson, Alan G. Robins, Dudley E. Shallcross, Robert J. Smalley, James E. Tate, Alison S. Tomlin, and Iain R. White

Dispersion of Air Pollution and its Penetration into the Local Environment (DAPPEE) refers to-studies focused on understanding the movement and mixing-of-airborne be material released into the complex urban environment.
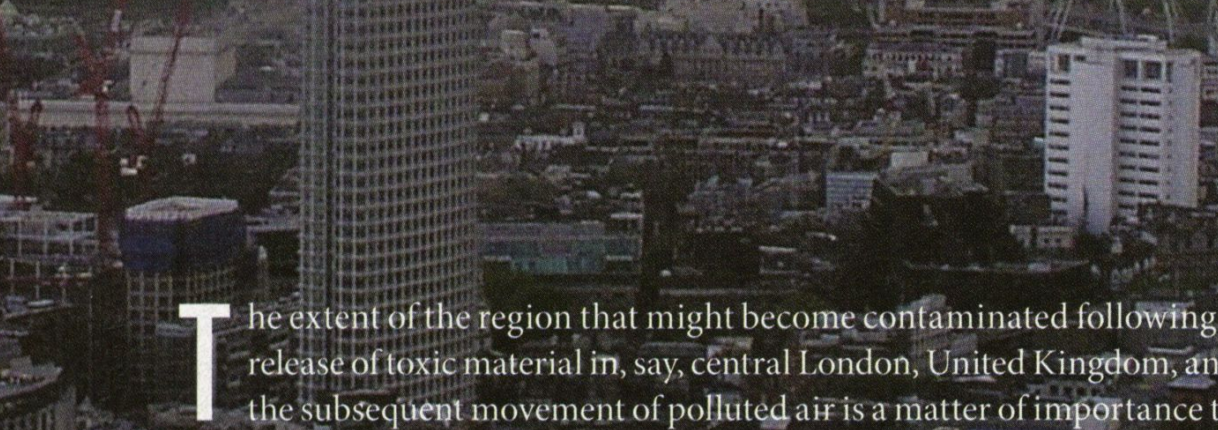

he extent of the region that might become contaminated following a
release of toxic material in, say, central London, United Kingdom, and release of toxic material in, say, central London, United Kingdom, and
the subsequent movement of polluted air is a matter of importance to U.K. emergency response planning, management, and training personnel. Knowledge of short-range dispersion behavior in the United Kingdom and similar northern European cities is clearly vital but is severely limited by the lack of pertinent experimental information. Results from studies in cities in the United States [e.g, Salt Lake City, Utah (Allwine et al. 2002; Doran etal. 2002), and Oklahoma City, Oklahoma (Allwwine et al. 2004)],

III while useful, are not directly applicable because of the great differences in city architecture and, perhaps to a lesser extent, the prevailing climatic conditions. Similarly, the extensive body of information-about flow and dispersion in regular obstacle arrays is also informative but not directly applicable because one of the, key features of the urban geometry is its irregularity, both in building height and plan dimensions.

Relevant tracer dispersion experiments in European cities have previously been carried out in Birmingham, United Kingdom (Britter et al. 2002); in Basel, Switzerland (Rotach et al. 2004); and also in London. The early London experiments formed part of the Engineering and Physical Sciences Research Council (EPSRC), United Kingdom-funded Dispersion of Air Pollution and its Penetration into the Local Environment (DAPPLE) project, which ran from 2002 to 2006 . Further information can be found

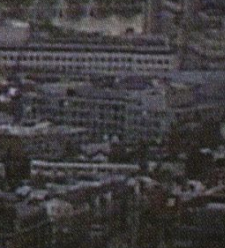




\begin{tabular}{|c|c|c|c|c|c|c|c|c|}
\hline \multirow{2}{*}{$\begin{array}{c}\text { Date and } \\
\text { start time } \\
\text { (LST) }\end{array}$} & \multicolumn{2}{|c|}{$\begin{array}{l}\text { Library rooftop } \\
\text { wind }\end{array}$} & \multirow{2}{*}{$\begin{array}{c}\text { Tracers } \\
\text { simultaneously } \\
\text { released }\end{array}$} & \multirow[b]{2}{*}{$\begin{array}{c}\text { Tracer } \\
\text { experiments }\end{array}$} & \multirow{2}{*}{$\begin{array}{c}\text { Samples } \\
\text { per site per } \\
\text { experiment }\end{array}$} & \multirow{2}{*}{$\begin{array}{c}\text { Bag sample } \\
\text { duration } \\
\text { (min) }\end{array}$} & \multirow[b]{2}{*}{$\begin{array}{c}\text { No. of } \\
\text { sample sites }\end{array}$} & \multirow{2}{*}{$\begin{array}{c}\text { Range of } \\
\text { distances } \\
\text { (m) from } \\
\text { source }\end{array}$} \\
\hline & $\begin{array}{l}\text { Speed } \\
\left(\mathrm{m} \mathrm{s}^{-1}\right)\end{array}$ & $\begin{array}{l}\text { Direction } \\
\left(\text { theta }^{\circ}\right)\end{array}$ & & & & & & \\
\hline $\begin{array}{l}15 \text { May } 2003, \\
1700\end{array}$ & 3.2 & -138 & 2 & 1 & 10 & 3 & 9 (+ roof) & $75-430$ \\
\hline $\begin{array}{l}3 \text { Jun } 2004, \\
1630\end{array}$ & 2.2 & +53 & 3 & 1 & 10 & 3 & $\begin{array}{l}14 \text { (+ roof }+ \\
\text { indoors) }\end{array}$ & $40-590$ \\
\hline $\begin{array}{l}4 \text { Jun } 2004, \\
1400\end{array}$ & 2.6 & +3 & 3 & 1 & 10 & 3 & $\begin{array}{l}14 \text { (+ roof }+ \\
\text { indoors) }\end{array}$ & $75-430$ \\
\hline $\begin{array}{l}2 \text { Nov } 2004, \\
1500\end{array}$ & 2.1 & +114 & 1 & 2 & 1 & 8 & 13 & $37-234$ \\
\hline $\begin{array}{l}\text { II Nov } 2004 \text {, } \\
1400\end{array}$ & 1.6 & -96 & 1 & 2 & 1 & 8 & 14 & $47-200$ \\
\hline $\begin{array}{l}30 \text { May } 2007 \\
1200\end{array}$ & 2.9 & +86 & 3 & 4 & 1 & 30 & 15 & $22-437$ \\
\hline $\begin{array}{l}06 \text { Jun } 2007, \\
1200\end{array}$ & 1.9 & -122 & 3 & 4 & 1 & 30 & 15 & $22-437$ \\
\hline $\begin{array}{l}07 \text { Jun } 2007, \\
1200\end{array}$ & 1.1 & -121 & 3 & 4 & 1 & 30 & 15 & $22-437$ \\
\hline $\begin{array}{l}28 \text { Jun } 2007 \\
1300\end{array}$ & 2.6 & +19 & 3 & 1 & 10 & 3 & 18 & $22-437$ \\
\hline $\begin{array}{l}13 \mathrm{Mar} 2008 \\
1100\end{array}$ & 2.3 & +33 & 1 & 8 & 1 & 30 & 14 & $40-280$ \\
\hline
\end{tabular}

many reports, videos, figures, maps, and text; but, in short, EPSRC-DAPPLE concentrated chiefly on personal human exposure to traffic pollutants (Arnold et al. 2004; Colvile et al. 2004), the effects of traffic and street layout on environmental turbulent flow

AFFiliations: WOOD, BARLOW, BeLCHER, AND DOBREUniversity of Reading, Reading, United Kingdom; TOMLIN, Balogun, Smalley, Lingard, AND TATE-University of Leeds, Leeds, United Kingdom; RoBINs-University of Surrey, Guildford, United Kingdom; CHENG-Building Research Establishment, Ltd., Watford, United Kingdom; ARNOLD-Golder Associates, Ltd., United Kingdom; Martin, Petersson, Shallcross, and WHITE-University of Bristol, Bristol, United Kingdom; BRITTER-University of Cambridge, Cambridge, United Kingdom; NeOPHYTOU-University of Cyprus, Nicosia, Republic of Cyprus A supplement to this article is available online (10.1175/2009BAMS2638.2) CORRESPONDING AUTHOR: Curtis R. Wood, Department of Meteorology, University of Reading, Earley Gate, P.O. Box 243, Reading RG6 6BB, United Kingdom

E-mail: c.r.wood@reading.ac.uk

The abstract for this article can be found in this issue, following the table of contents.

DOI:10.1175/2009BAMS2638.1

In final form 23 February 2009

(02009 American Meteorological Society within street canyons (Dobre et al. 2005), and both fixed- and moving-source tracer dispersion experiments (Arnold et al. 2004; Martin et al. 2008).

The EPSRC-DAPPLE studies did not yield a sufficiently extensive database of tracer dispersion experiments that could be used unambiguously for evaluating modeling techniques or for probing in detail the dispersion processes and their variability. Field tracer experiments of the type considered here have to be classified as individual realizations in conditions that seldom, if ever, repeat. However, given a large enough number of such realizations, it is possible to derive robust features of dispersion behavior, and it is these features that models need to predict. It should also be possible to assess the bias, if not scatter, in model predictions, because this will be dominated by variability in the observations. In the wind tunnel, large ensembles can be obtained in identical experimental conditions and model performance can be assessed based on the statistical properties of the ensembles.

The overriding objective of the 2007 work (summarized in this article) was to use our capability to help build a larger database of tracer studies at a single site in London and then to find relationships 
describing the spatial patterns of concentration away from a source of emitted material. Appropriate fieldwork, from 2002 to 2007 and beyond, has been successfully undertaken in central London (Table 1) and has established a multidisciplinary research capability in the United Kingdom that is capable of combined urban tracer dispersion trials, micrometeorological fieldwork, wind tunnel simulation studies, and a range of computational modeling. Using the same tracer release methodology (see the "Tracer Methodology" section), the total number of DAPPLE full-scale tracer studies successfully undertaken has exceeded 50 , including both fixed-source and novel movingsource experiments. Any parties wishing to make use of our database should view our Web site and contact Professor Alan Robins (info@dapple.org.uk) in the first instance.

Since the primary aim in 2007 was to obtain data at street level and to make best use of the limited number of sampling units available, the investigation of vertical dispersion is not included in this article. In particular, the loss of tracer to the flow above roof level, and the subsequent dispersion in the boundary layer, will be investigated by wind tunnel and largeeddy simulation (LES) computational fluid dynamics (CFD) modeling. Rooftop release and measurements of tracer have been conducted in previous DAPPLE work, which indicated well-mixed conditions within the street canyons (Martin et al. 2008).

The purpose of this article is to give an overview of the experimental design and methodology for full-scale tracer dispersion experiments and to present some early results from the 2007 campaign. The following four scientific questions are addressed in this article: i) What scientific principles are needed to design such experiments? ii) What is the rate of decrease in tracer concentration away from the source? iii) How is the extent of the plume affected by the interaction between mean above-roof winds and flow modification as a result of the geometry of the street network? iv) What, if any, simple guidelines for dispersion behavior can be made that can inform emergency planning and response?

\section{FULL-SCALE DISPERSION EXPERIMENTS}

2007. The fieldwork objectives were to i) release a nontoxic tracer gas, ii) ascertain the tracer concentration within the local street network, and iii) analyze the tracer concentrations in conjunction with wind and turbulence information.

The experimental work took place in central London (Fig. 1). The two major roads in the vicinity are Marylebone Road, which runs $17^{\circ}$ anticlockwise from west to east, and Gloucester Place, which intersects perpendicularly with Marylebone Road near the DAPPLE operations center in the Westminster City Council (WCC) building. Marylebone Road forms the northern boundary of the central London congestion charging zone and has three lanes of busy traffic in each direction (flow rates of 3,000-3,400 vehicles per hour are typical on weekdays). Gloucester Place is three lanes in width and traffic is one-way northward. The mean building height in the study area is $21.5 \mathrm{~m}$

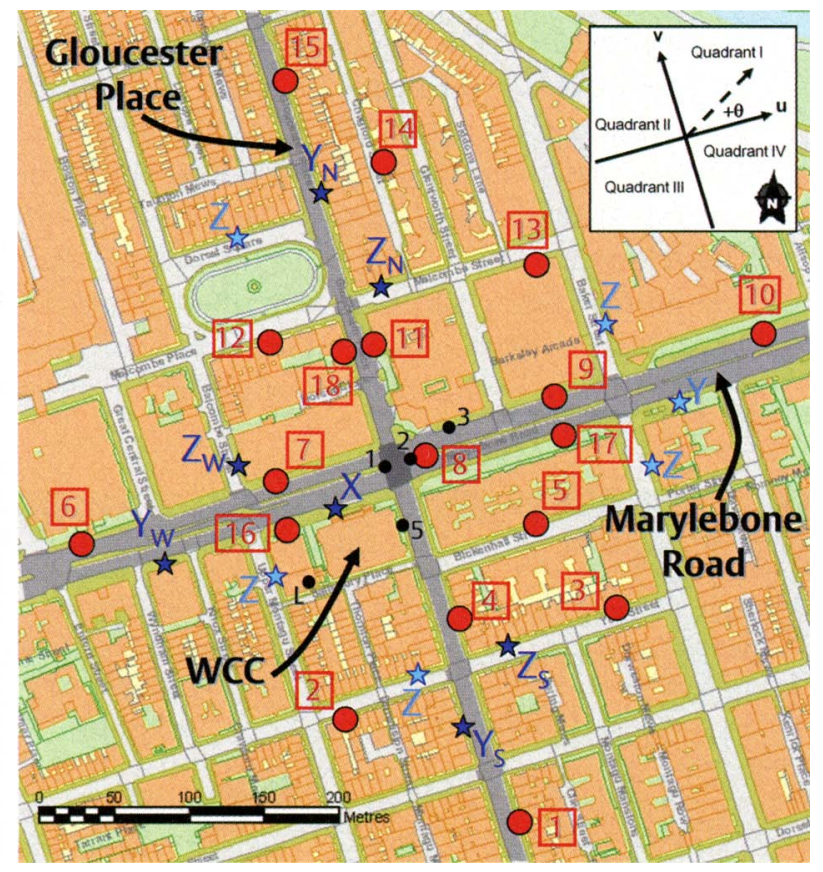

FIG. I. The map shows the DAPPLE area of central London, and is centered at the focal intersection, that of Marylebone Road and Gloucester Place (at $51.5218^{\circ} \mathrm{N}, 0.1597^{\circ} \mathrm{W}$ ). Also shown are the locations used in the summer 2007 campaign. The sampling receptors are numbered I-19 (red circles). On each tracer day, there were three fixed-point tracer sources (blue stars). There was always a release at location $X$ outside the Westminster City Council building. The release points at sites $Y$ and $Z$ varied depending on the wind direction, so that the releases from sites $Y$ and $Z$ on a given day were planned to be upwind of most of the receptors; the dark blue stars are the locations actually used (on tracer day $I$, the south tracer release sites were used on days 2 and 3 north, and day 4 west). Ultrasonic anemometers (marked with black dots) were located atop Westminster City Council Library rooftop (L), around the focal intersection (intersection sites labeled I-3 and 5), and at tracer release sites (see text). (top right) The inset shows the DAPPLE street coordinate system for wind vectors: theta is defined with respect to Marylebone Road and is positive anticlockwise (Dobre et al. 2005). The base map is an Ordnance Survey/EDINA supplied service (๑) crown copyright/database right 2008). 
(with a range of 10-64 m). The experimental site was chosen because the site required a diameter of approximately $500 \mathrm{~m}$ to cover the range of near-field dispersion.

Tracer methodology. Three detectably different perflurocarbon (PFC) tracers were used in this work (see "Tracers for environmental flow analysis" for more information): perfluoromethyl-cyclohexane (PMCH, $\mathrm{C}_{7} \mathrm{~F}_{14}$ ), para-perfluorodimethyl-cyclohexane (p-PDMCH, $\mathrm{C}_{8} \mathrm{~F}_{16}$ ), and meta-perfluorodimethylcyclohexane ( $\left.\mathrm{m}-\mathrm{PDMCH}, \mathrm{C}_{8} \mathrm{~F}_{16}\right)$. They were obtained as pure liquids (F2 Chemicals, Ltd.) from which appropriate gravimetric dilutions were prepared (Linde Gases, Ltd.). The street-side release apparatus comprised a stainless steel 15 -L silica-lined canister (Restek, Ltd.), which was connected to a pressure transmitter (Series 33X, Keller UK, Ltd.). A specialist software program monitored the output from the pressure transmitter; temperature dependencies and nonlinearity of the sensors were mathematically compensated for after the release. Components were connected together using stainless steel tubing (3.18-mm outer diameter and 2.16-mm inner diameter, Swagelok, Ltd.). The gas flow rate was controlled by the use of a Flostat flow controller (type MNBS12, Roxspur Measurement and Control, Ltd.). The flow controller was used to maintain a constant flow when the supply pressure varied but where the discharge pressure was relatively constant (in our case, to the atmosphere). The release rate $Q$ was recorded and ranged from 60 to $359 \mu \mathrm{g} \mathrm{s}^{-1}$. The total mass emitted $M$ from each point-source release ranged from 54 to $323 \mathrm{mg}$, according to experimental requirements. The extreme sensitivity of the tracer detection system implied that these very low tracer emission rates could be used, something that greatly simplified the planning procedures for the fieldwork. The choice of emission rate was determined by preliminary wind tunnel work (Robins and Cheng 2003) and a simple

\section{TRACERS FOR ENIVIRONMENTAL FLOW ANALYSIS}

A tracer gas suitable for full-scale experiments must be i) A invisible, odorless, and nontoxic, so that there is no cause for concern or disruption to the public; ii) nonreactive and nondepositing on long time scales, so that it disperses as a passive tracer in the flow; and iii) readily detectable, so that the concentrations can be measured at the required distances away from source. Ideally, the background concentration should be very small and constant, so that only a small amount of tracer needs to be used to overpower the background signal.

Trace gases that satisfy these requirements and that are often used in full-scale dispersion studies are cyclic perfluoroalkanes (PFCs) and sulfur hexafluoride $\left(\mathrm{SF}_{6}\right)$. PFCs have been used in many studies to determine source-receptor relationships (e.g., Lovelock and Ferber 1982; D'Ottavio et al. 1986; Logomarsino 1996; Dietz 1986). Both PFCs and SF are inert (certainly on much greater time scales than apply to our experiments), nontoxic, nondepositing, invisible gases and-especially in the quantities to be used-have no local environmental effects. However, they are gases with high global warming potentials (GWPs), which must be considered. Table SBI presents climate effect information for the PFC and $\mathrm{SF}_{6}$ tracer emissions used in DAPPLE experiments. GWPs for particular PFCs are not always available, and thus the table shows calculations based on a PFC with a typical high GWP to illustrate the point. A further important point is that PFCs have "zero ozone depletion potential" (Tsai et al. 2002).

Background concentrations of PFCs are extremely low; for example, $\mathrm{PMCH}$ has a background concentration of $\sim 5$ parts per quadrillion (ppq; I part in $10^{15}$ ). This, together with the extremely sensitive detection techniques, implies that a release of around 200 times less (by mass) can be compared with a release of $\mathrm{SF}_{6}$, which leads to a considerable reduction in the global warming effect of tracer experiments using PFCs rather than $\mathrm{SF}_{6}$ (see Table SBI). Since there are fewer concerns with the use of PFCs compared with $\mathrm{SF}_{6}$, only PFC tracers were used from 2007 onward in DAPPLE fieldwork. Regulations have also been introduced in Europe to reduce emissions of gases with high GWPs, which apply to $\mathrm{SF}_{6}$ and some PFCs but not to those used in the 2007 fieldwork [for further details, see European Community (EC) Regulation No. 842/2006 on Certain Fluorinated Greenhouse Gases].

\begin{tabular}{|c|c|c|}
\hline Item & $\mathrm{SF}_{6}$ & PFC \\
\hline $\begin{array}{l}\mathrm{CO}_{2} \text { equivalence (global warming } \\
\text { potential for } 100 \text { years) }\end{array}$ & 22,800 & 12,200 \\
\hline Lifetime in the atmosphere $(\mathrm{yr})$ & 3,200 & 50,000 \\
\hline $\begin{array}{l}\text { Approximate release needed per } \\
\text { experiment }\end{array}$ & $100 \mathrm{~g}$ & $500 \mathrm{mg}$ \\
\hline $\begin{array}{l}\text { Total tracer release for } \\
30 \text { experiments }\end{array}$ & $3 \mathrm{~kg}$ & $15 \mathrm{~g}$ \\
\hline Total $\mathrm{CO}_{2}$ equivalent & 68.4 tons & $183 \mathrm{~kg}$ \\
\hline
\end{tabular}


correlation relationship based on existing urban dispersion data (Neophytou and Britter 2004; see also forthcoming discussion).

Mean above-roof winds came from a range of directions during the campaign periods. In anticipation of that, the tracer release and sampling methodology was designed to be flexible, so that an appropriate strategy could be selected according to the most up-to-date forecast on the morning of each day of a planned tracer release (the tracer days). On tracer days, a unique PFC tracer type (mentioned earlier) was emitted from each of the three release sites: $\mathrm{X}, \mathrm{Y}$, and $\mathrm{Z}$. The post-experiment laboratory analysis was able to discriminate between each tracer type from a single sample; thus, three concentration values were recorded in each sample. Site $X$ was near the center of the site and was surrounded by sampling receptors (the red circles in Fig. 1). Site X was fixed for the $2007 / 08$ campaigns. Four potential release sites were planned for site $Y$, so that its release was i) upstream of most of the receptors and ii) on the major street canyon that ran parallel to the largest vector component of the mean above-roof flow (either Gloucester Place or Marylebone Road). The third release site, Z, was subsequently selected and located on a narrower and less-trafficked side street that was close to the chosen $Y$ site. Hence, $Z$ releases were also upwind of most receptors and were in streets that were perpendicular to the major street canyon in which site $Y$ was located. In this way, a comparison can be made of the dispersion patterns from two nearby release points located in streets perpendicular to one another under the same meteorological conditions.

Release sites $\mathrm{Y}$ and $\mathrm{Z}$ were chosen and fixed for the run of experiments conducted during each tracer day. This choice was based on analysis of the weather forecast on the preceding day and on-site conditions on the tracer day. This strategy was chosen so that the receptor sites were fixed for all tracer days and that only the tracer source locations were varied. This simplified the logistics, because each receptor required a person to oversee the sampling. Furthermore, the release sites $\mathrm{Y}$ and $\mathrm{Z}$ were specifically chosen to be midway along the length of their respective street canyons. Release locations near intersections were specifically excluded because of the local variability in flow and dispersion on very-short spatial scales [of, say, less than one building height from the source; see Belcher (2005)]. Releases from intersections were not suited to our objective because a much larger database would be required in such locations, beyond the resources available. Wind tunnel studies are better suited to conducting such work because experimental conditions are fully controlled and repeatable (Robins et al. 2002).

To fully understand (and model) the spread of the tracer, information would be required on horizontal and vertical structures of the plume. However, the 2007 experiments were designed to discover information on the reduction of contamination away from the source at the street level, which is important for the exposure of humans in the urban environment to contamination. Thus, at street level, a network of up to 18 air sampling receptors was positioned in the local street network on tracer days. Straightline source-receptor distances were in the range of 22-437 m, with a mean of $189 \mathrm{~m}$. Several receptors were located along the major roads (Marylebone Road and Gloucester Place) where flow channeling parallel to the mean above-roof wind was expected (Dobre et al. 2005; Belcher 2005). Some receptors were located upwind of the sources because some upwind transport is expected in the complex local flow field (see "Effects of the above-roof flow and street network layout on in-street flow" for more information). There were three sets of paired receptor sites on opposite sides of the major roads (receptors $7 / 16,9 / 17$, and 11/18) deployed on tracer day 4 to assess how well mixed the tracer was across streets that were parallel to the mean above-roof wind direction and to probe the effects of canyon vortices in streets perpendicular to the mean above-roof wind.

An operator remained at each receptor site for the duration of the deployment, for safety and security purposes. At each such site, the inlet to an air sampling pump (SKC, Ltd.) was connected to a hose that sampled air from 1-m height. The outlet was attached to a 5-L sampling bag (Tedlar) for each required sample. At predetermined times-read from radio-synchronized clocks-all personnel across the DAPPLE site simultaneously attached new bags to the sampling pumps. These were filled during a fixed period and then detached from the pumps and stored. Physical isolation of the release and sampling teams was ensured at all times before, during, and after experiments to avoid corruption of the collected air samples.

The release and sampling strategy was changed on different days to allow different experiment types to be conducted. Dosage experiments were carried out on the first three tracer days (31 May and 7 and 8 June 2007), whereas the experiment on 28 June was time resolved. For the dosage (time integrated) experiments, there were typically four sets of 45 -min measurement cycles conducted during each tracer day. Each set was composed of a tracer release from 


\section{EFFECTS OF THE ABOVE-ROOF FLOW AND STREET NETWORK LAYOUT ON IN-STREET FLOW}

fundamental street network component is the street A canyon: a long, narrow street, of $H$ and $W$, with buildings on either side, as illustrated in Fig. SBI. Local time-averaged flow depends upon the incident wind direction relative to the canyon. a) When the mean above-roof wind has a substantial component perpendicular to the canyon, a vortex occurs in the time-averaged flow with a shear layer near
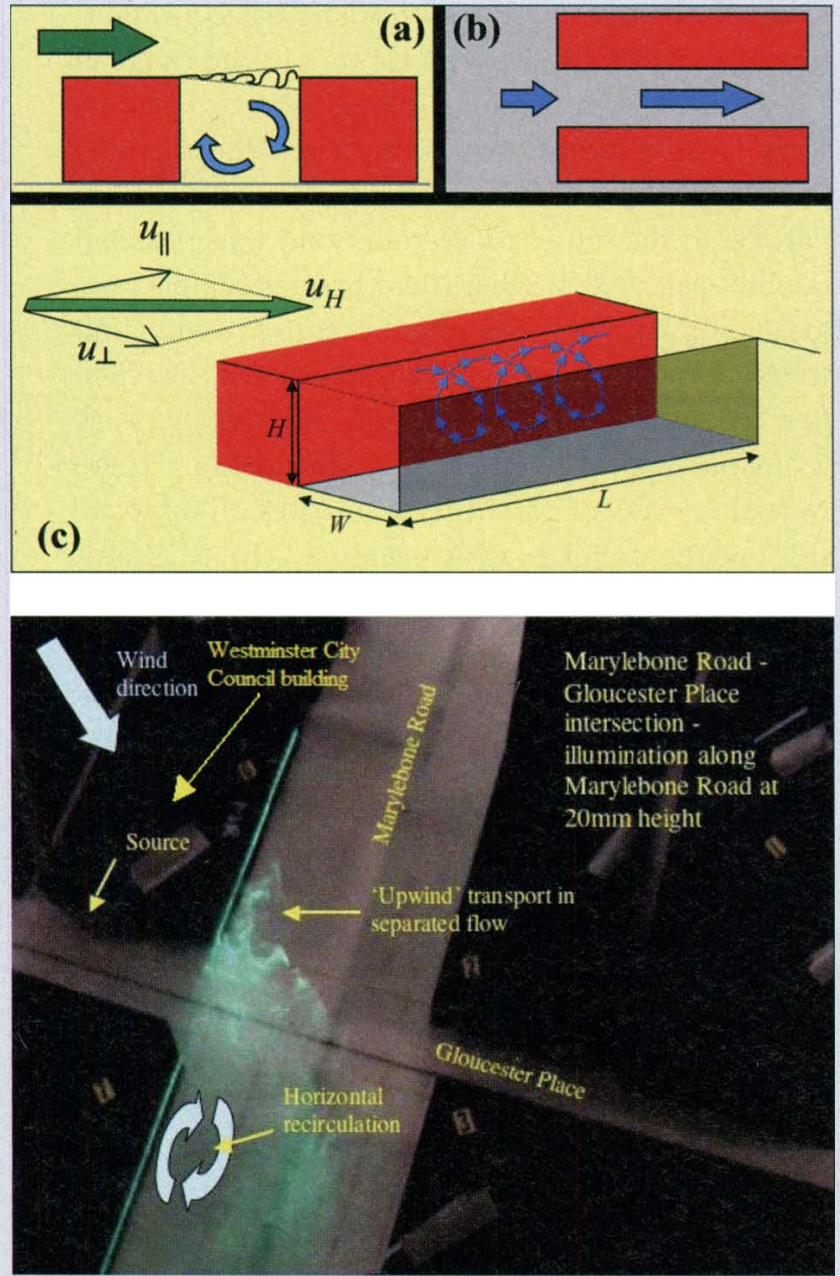

roof level. b) In contrast, when the mean above-roof wind is mainly parallel to the street canyon, channeling flow results. In channeling flow conditions, the components of the wind in the vertical and cross-street directions are small compared with the component along the length of the street. For c), oblique flow, a blend of the two features for parallel and perpendicular flow results in helical flow in the time mean (e.g., Dobre et al. 2005). Note that these time-averaged descriptions mask great unsteadiness in the flow and the intermittent exchange of air with the flow above the canyon.

Another fundamental street network component is the intersection. Intersection flow is generally less well understood, and a general description has not yet been formulated. For flow perpendicular/parallel to the streets forming an intersection, the proposed view is that there is channeling along the street parallel to the wind and with canyon vortices in the perpendicular street, with little penetration of pollutant from the one street canyon into the other. For oblique flow, DAPPLE and related work has revealed several key features, some of which are illustrated in Figs. SB2 and SB3 and the associated movie (online at doi:10.1175/2009BAMS2638.2). There is a strong, threedimensional interaction between the flows into the intersection from the street network, resulting in increased turbulence levels and vertical motions that enhance the exchanges between both the street canyons systems and the above-roof flow. Extensive horizontal recirculation regions form that are major features of the inhomogeneous mixing conditions, as clearly seen in Fig. SB2.

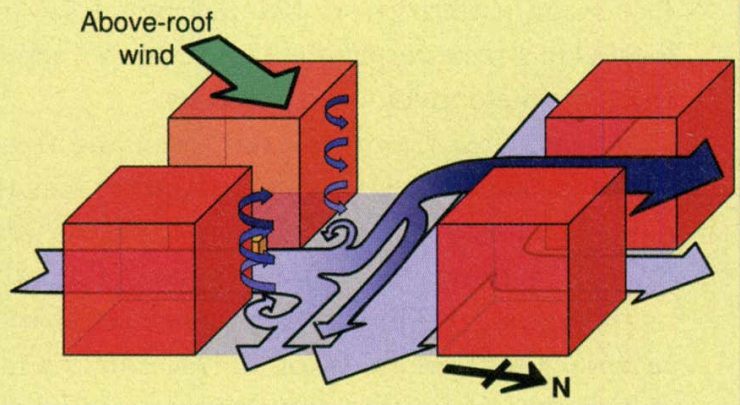

FIG. SBI (TOP LEFT). Flow regimes in street canyons (Belcher 2005): (a) a side view for mean above-roof flow perpendicular to the street canyon; (b) a plan view for mean above-roof flow parallel to the street canyon; (c) a 3D view for oblique flow (the mean above-roof wind vector is shown together with the components parallel and perpendicular to the canyon). The wavy line in (a) represents intermittency in the shear layer at roof level; the blue arrows in (c) show a street canyon vortex. The channeled flow in (b) is shown in the street canyon.

FIG. SB2 (воттом LEFT). An annotated photograph from the flow visualization in the University of Surrey's EnFlo wind tunnel (see Robins et al. 2004). A laser light sheet illuminated a horizontal plan along Marylebone Road to show the horizontal component of the flow at the intersection. Smoke was injected as marked from a source in Gloucester Place. At the height of illumination, $0.2 \mathrm{H}$, smoke in the region shown was confined mainly to the south side of Marylebone Road. An extensive, horizontal recirculation was formed downstream from the junction on the south side of the road. Smoke was also seen upstream in a recirculation region in the wake of the Westminster City Council building. Intermittent "shear layer" vortices were apparent in the video of this flow and were associated with this "upwind" transport.

FIG. SB3 (RIGHT). Schematic representation of the flow inferred from the wind tunnel visualization for an oblique flow across an intersection [see also Fig. SB2 and movie (doi: 10.1175/2009BAMS2638.2)]. Darker blues are used for flows of tracer at higher elevations and lighter blue for near the street level. There is, of course, continuous small-scale mixing between these mean flow features. The position of the wind tunnel smoke source is shown by an orange cube (see also Fig. SB2 for clarity). 
0 to $15 \mathrm{~min}$, concurrent with sampling from 0 to $30 \mathrm{~min}$, followed by a $15-\mathrm{min}$ period with no release or sampling to ensure that tracer levels in a street network returned to background levels (a schematic is shown of this release and a sampling schedule in Fig. 4). The number of dosage experiments per tracer day was maximized by the careful choice of release rate and duration (hence the mass of release), so that tracer concentrations returned to background levels between experiments while ensuring that measurable tracer levels above the background were seen over the distances involved. Extra background samples were taken between experiments to confirm that reduction to background levels had been achieved. For the timeresolved experiment, there was one 30-min experiment in which the release ran from 0 to $15 \mathrm{~min}$. Ten 3 -min sampling sets were taken during minutes $0-30$. Each set was composed of a 2.5-min sample, followed by $30 \mathrm{~s}$ of nonsampling to allow operators the time needed to change sample bags (a schematic is shown of this release and a sampling schedule in Fig. 5). Very few samples were lost; overall, there were $92 \%$ successful bag analyses from the intended samples.

Tracer analysis. Off-site analytical instrumentation was used to determine tracer concentrations. A gas chromatograph (GC; model 6890, Hewlett Packard, Ltd.) was attached to a mass selective detector (model 5973, Hewlett Packard, Ltd.), and PFC concentrations were obtained with the mass spectrometer operated in negative-ion chemical ionization mode (NICI) as well as selected ion-monitoring (SIM) model. An adsorption-desorption system (ADS) based on the design in Bassford et al. (1998) was used for sample trapping and desorption. The ADS encompassed all of the electronics, electrically actuated valves, mass flow controller, air sampling pump, and ancillary software to analyze bag samples and calibration standards in a repetitive sequence. Samples were cryogenically adsorbed $\left(-50^{\circ} \pm 3^{\circ} \mathrm{C}\right)$ onto a stainless steel microtrap that contained $10 \mathrm{mg}$ of a carbon-based adsorbent Carboxen 569, with a 40-50 mesh (Supelco). Under these analytical conditions, several liters of PFC could be quantitatively trapped on to the microtrap without exceeding the theoretical breakthrough volume (BTV). Because of the small volume of the microtrap $(\sim 100 \mu \mathrm{l})$ and the relatively large volume of the air samples, there was a substantial sample preconcentration, which enhanced the sensitivity of the analytical method. Samples were then quantitatively desorbed at $255^{\circ} \mathrm{C}$ to the GC column. The analytes were separated using a $30 \mathrm{~m} \times 0.32 \mathrm{~mm}$ graphitized carbon (Carbograph) PLOT capillary column (LARA s.r.l.). A more complete description can be found in Simmonds et al. (2002).

Flow measurements. Flow data were obtained to give the following three main products: i) in-street mean velocity and turbulence conditions, ii) estimates of sensible heat flux and thus atmospheric stability, and iii) reference speeds used for nondimensionalizing concentration and dosage data. Eleven ultrasonic anemometers (R2 and R3 research-grade Gill Instruments) were deployed to provide 3D winds and virtual temperature at $10-20 \mathrm{~Hz}$ for these purposes. The anemometers were logged either with a Campbell CR1000 logger or directly to laptops via serial/ Universal Serial Bus (USB) ports.

Two of the anemometers were installed at reference sites: tower top and rooftop. The tower-top instrument was mounted at a height ${ }^{1}$ of $190 \mathrm{~m}$ on a lattice mast at the top of the British Telecom (BT) tower $\left(51.5215^{\circ} \mathrm{N}, 0.1389^{\circ} \mathrm{W}\right)$, which is about $1.5 \mathrm{~km}$ east of the DAPPLE central area (note there are no other comparably tall buildings in the vicinity of the DAPPLE and BT tower area). The other reference was mounted on the roof of the Westminster City Council Library $\left(51.5210^{\circ} \mathrm{N}, 0.1605^{\circ} \mathrm{W}\right)$; the roof height is $15.5 \mathrm{~m}$, and the anemometer head was an additional $2.9 \mathrm{~m}$ above the rooftop. The relationship between the two reference measurements was analyzed to determine which was most appropriate for characterizing conditions within the street canyons. The data can also be used to discover if, and under what conditions, the flow in the roughness sublayer immediately above the roof becomes decoupled from the flow aloft. There were six anemometers around the focal intersection (i.e., where Gloucester Place meets Marylebone Road) to probe the flow structure at a complex intersection (Fig. 1). There were pairs of anemometers at sites 1 and 2 (each at 4 and $7 \mathrm{~m}$ above street level), and single anemometers at sites 3 and 5 (at $4 \mathrm{~m}$ ) and also at each release site at a height of $1 \mathrm{~m}$ (sites Y and Z) or $1.5 \mathrm{~m}$ (site X). The street-level data provided information on the initial dispersion behavior and helped diagnose local flow features (see "Effects of the above-roof flow and street network layout on in-street flow").

ANALYSIS OF FLOW AND TURBULENCE. Reference winds. The climatology of wind speeds at rooftop $(18.4 \mathrm{~m})$ and tower top $(190 \mathrm{~m})$ measured throughout 2007 is shown as a scattergram in

\footnotetext{
${ }^{1}$ All heights in this article are above ground level, unless otherwise stated.
} 


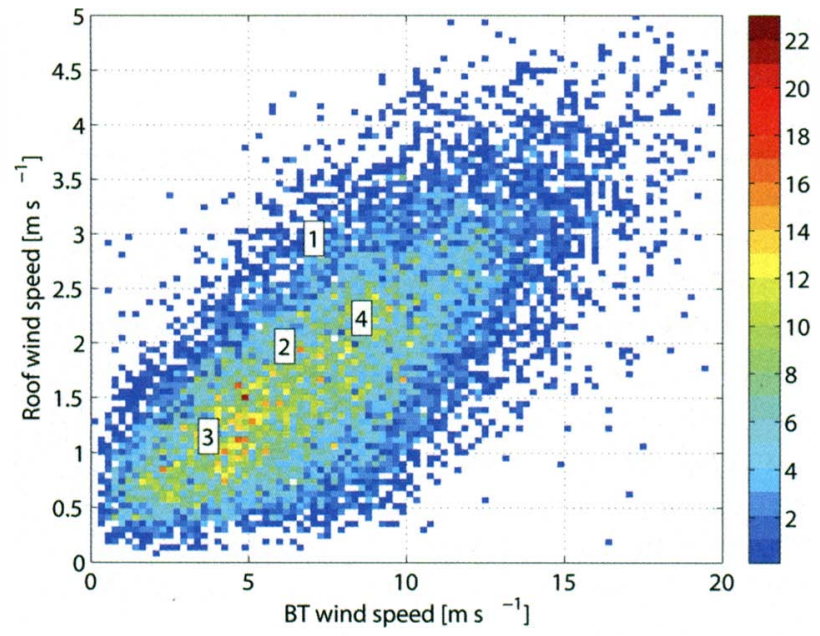

FIG. 2. Scattergram of 2007 (whole year) 15-min mean wind speeds at rooftop and tower top over all periods of the day (12,619 samples available for analysis). The data were binned into $100 \times 100$ cells (hence, bins are $0.05 \mathrm{~m} \mathrm{~s}^{-1}$ for roof data and $0.2 \mathrm{~m} \mathrm{~s}^{-1}$ for tower data). The colors (see color bar) are the number of $15-\mathrm{min}$ mean samples per bin. The ratio of the means of the two datasets is 4.1 (a slope of $\mathbf{5 . 7}$ was found when a linear regression was performed on the $15-\mathrm{min}$ mean data). The daytime mean wind speeds on the four tracer days are marked (see also Table 2).

Fig. 2. The 15-min mean wind speeds are $7.4 \mathrm{~m} \mathrm{~s}^{-1}$ at tower top and $1.8 \mathrm{~m} \mathrm{~s}^{-1}$ at rooftop, which is a factor of 4.1 slower at rooftop. Sector analysis showed that this ratio was not related to wind direction; indeed, some of the spread might be due to changes in atmospheric stability (cf. Klein and Clark 2007). The associated 2007 climatology of wind direction is shown in Fig. 3. The wind direction veers (turns clockwise), with height from rooftop to tower top, by a mean angle of $9^{\circ}$. Recognizing this veering is important in interpreting wind vectors from a refer-

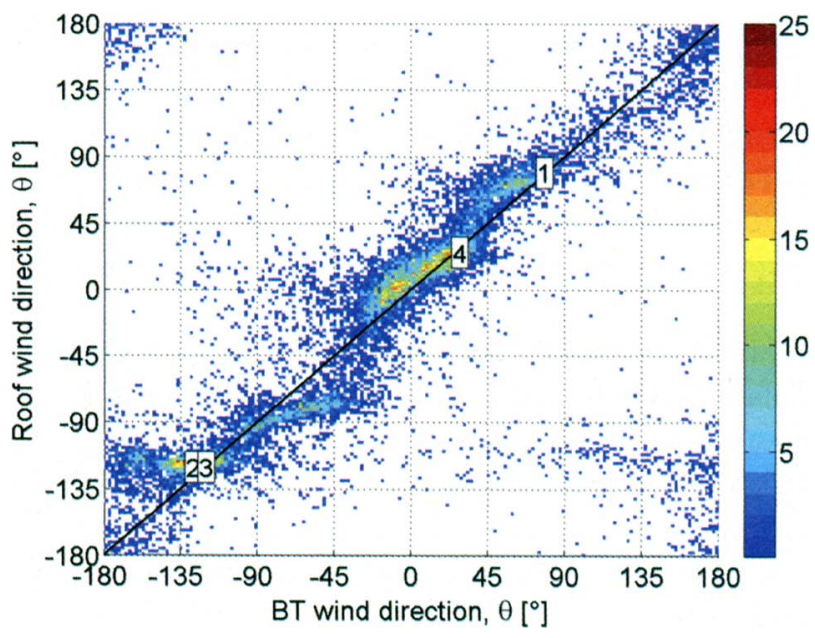

ence site, particularly for emergency response and planning purposes. Figure 3 shows that there were two directions (centered at the rooftop at $-130^{\circ}$ and $-80^{\circ}$ ) where the rooftop wind direction did not vary given substantial variations in the tower-top wind direction.

Reference sites in urban areas will always be effected by some flow distortion due to local buildings. Detailed sector analysis suggested that the rooftop wind direction displayed anomalies related to certain channeling or wake effects associated with individual buildings located upwind of the rooftop site. Because the height of the rooftop reference wind measurement was only $2.9 \mathrm{~m}$ above the roof, it is likely that the wind measurements were affected by rooftop flow distortion [further details of rooftop flow distortion are in Barlow et al. (2009)]. The effects of flow distortion have not been considered in the data analysis shown in this article. This distortion might affect both the wind speed ratio (4.1) and the degree of veering of the wind with height $\left(9^{\circ}\right)$. A combination of wind tunnel, field, and LES CFD work is being used to address this issue.

Campaign winds. General flow characteristics on the tracer days are illustrated in Tables 2 and 3, and the reference wind speeds and directions measured are marked in Fig. 2 and 3. On the tracer days, the wind directions coincided with the predominant conditions (Fig. 3). Wind speeds occurred near the center of the distribution on tracer days $2-4$, but anomalously fast winds at rooftop relative to tower top occurred on tracer day 1 . Note also that tracer days 2 and 3 had the same wind direction but different wind speeds and atmospheric stabilities (see Table 2); thus, detailed analysis of these days might aid interpretation of the full-scale variability of concentration data for a given flow direction.

Figure 4 illustrates dispersion and wind conditions on tracer day 1 . Given the information in Table 2, the nature of the street-level mean flow (the blue vectors) was as expected given the mean above-roof winds

Fig. 3. Scattergram of 2007 (whole year) wind direction (for coordinate system; see inset in Fig. I) at rooftop and tower top over all periods of the day $(12,619$ samples available for analysis). The data are binned into $2^{\circ}$ cells. The colors (see color bar) are the number of $15-\mathrm{min}$ mean samples per bin. The thicker black diagonal is the $1: 1$ line. There is a mean veer in wind direction between the sites of $9^{\circ}$. The four tracer days are marked and coincide with predominant wind directions (see also Table 2). 
TABLE 2. Summary of 15-min mean flow conditions [calculated using a double-rotation streamwise analysis, following section 4 in Wilczak et al. (2001)] for 2007 tracer-day periods (typically II00I330 UTC). Sensible heat and stability calculated as per Kaimal and Finnigan (1994). Note that drag coefficient values expected using the Roth (2000) formulation are $C_{D}^{\text {roof }}=0.25$ and $C_{D}^{\text {tower }}=0.09$. Wind data are shown with $\pm \mathrm{I}$ standard deviation computed from the $\mathbf{2 0}-\mathrm{Hz}$ ultrasonic anemometer data.

\begin{tabular}{|c|c|c|c|c|c|}
\hline Tracer day & & I & 2 & 3 & 4 \\
\hline $\begin{array}{l}\text { Choices (direction) for tracer re- } \\
\text { lease (sites Y and Z; see Fig. I) }\end{array}$ & & $S$ & $\mathrm{~N}$ & $N$ & W \\
\hline Date (2007) & & 31 May & 7 Jun & 8 Jun & 28 Jun \\
\hline Sensible heat $H_{s}\left(\mathrm{~W} \mathrm{~m}^{-2}\right)$ & Tower & 240 & 73 & 187 & 73 \\
\hline Stability parameter $z / L$ & Tower & -2.1 & -5.3 & -3.7 & -2.2 \\
\hline \multirow{2}{*}{ Mean wind speed $U\left(\mathrm{~m} \mathrm{~s}^{-1}\right)$} & Tower & $6.9 \pm 1.2$ & $6.1 \pm 0.9$ & $3.1 \pm 1.0$ & $8.7 \pm 1.0$ \\
\hline & Roof & $2.9 \pm 1.6$ & $1.9 \pm 1.2$ & $1.1 \pm 0.9$ & $2.6 \pm 1.7$ \\
\hline \multirow{2}{*}{$C_{D}=\left(\sqrt{\bar{u}^{\prime} w^{\prime 2}}+{\overline{v^{\prime} w^{\prime}}}^{2}\right)$} & Tower & 0.11 & 0.07 & 0.18 & 0.05 \\
\hline & Roof & 0.15 & 0.25 & 0.28 & 0.18 \\
\hline \multirow{2}{*}{ Mean wind direction $\theta\left({ }^{\circ}\right)$} & Tower & $+77 \pm 44$ & $-133 \pm 44$ & $-123 \pm 40$ & $+29 \pm 51$ \\
\hline & Roof & $+86 \pm 48$ & $-122 \pm 50$ & $-121 \pm 45$ & $+19 \pm 37$ \\
\hline
\end{tabular}

TABLE 3. Characteristics used to aid qualitative analysis of in-street turbulence and dispersion. See also Table 2.

\begin{tabular}{|c|c|c|c|c|c|}
\hline Tracer day & & I & 2 & 3 & 4 \\
\hline $\begin{array}{l}\text { Choices (direction) for tracer release } \\
\text { (sites Y and Z; see Fig. I) }\end{array}$ & & $S$ & $N$ & $N$ & $w$ \\
\hline Date (2007) & & 31 May & 7 Jun & 8 Jun & 28 Jun \\
\hline \multirow{3}{*}{$\begin{array}{l}\text { Flow type expected: channeling flow }(\Rightarrow) \text { up } \\
(\uparrow) \text { or down }(\downarrow) \text {. Traffic-heavy sites are also } \\
\text { indicated ( })\end{array}$} & $(\Leftrightarrow) X$ & $\uparrow$ & $\downarrow$ & $\downarrow$ & $\Rightarrow$ \\
\hline & $(\risingdotseq) \mathrm{Y}$ & $\Rightarrow$ & $\Rightarrow$ & $\Rightarrow$ & $\Rightarrow$ \\
\hline & Z & $\downarrow$ & $\uparrow$ & $\uparrow$ & $\downarrow$ \\
\hline \multirow{3}{*}{ Height-to-width ratio of canyon $(H / W)$} & $\mathrm{X}$ & 0.33 & 0.33 & 0.33 & 0.33 \\
\hline & $\mathrm{Y}$ & 0.93 & 1.02 & 1.02 & 0.65 \\
\hline & Z & 1.43 & 1.49 & 1.49 & 1.41 \\
\hline
\end{tabular}

(the red vectors). In particular, tracer day 1 had strong flow northward across the site, with channeling flow northward along Gloucester Place evident at site Y. In the street perpendicular to the mean above-roof wind at site Z (York Street), there was a combination of recirculation plus some flow along streets perpendicular to the mean above-roof wind (see Dobre et al. 2005).

RESULTS OF THE TRACER MEASUREMENTS. To be able to compare the full-scale measurements of tracer concentration with results from the scaled wind tunnel model, it is necessary to make the concentration dimensionless. A rational method of nondimentionalization follows from the conservation of mass of emitted tracer. In the steady state, the flux of tracer from the source $Q\left(\mathrm{~kg} \mathrm{~s}^{-1}\right)$ must balance the flux advected through any plane perpendicular to the mean wind direction. Mathematically, this can be written as

$$
Q=\int_{0}^{\infty} \int_{-\infty}^{+\infty} U C \mathrm{~d} y \mathrm{~d} z,
$$

where $U$ is the wind speed $\left(\mathrm{m} \mathrm{s}^{-1}\right), C$ is the concentration $\left(\mathrm{kg} \mathrm{m}^{-3}\right)$, and $y$ and $z$ are the lateral and vertical coordinates, respectively. Thus, nondimensionalization was made by choosing an appropriate wind speed and length scale. Since we focused on the near field, we expected the urban geometry to control the dispersion rather than, for example, boundary layer depth. Furthermore, since the wind tunnel model is a scaled representation of the real geometry, any linear dimension representative of the real geometry will suffice. Here, we chose the mean building height $H$ to make the $y$ and $z$ dimensionless in Eq. (1). It was 


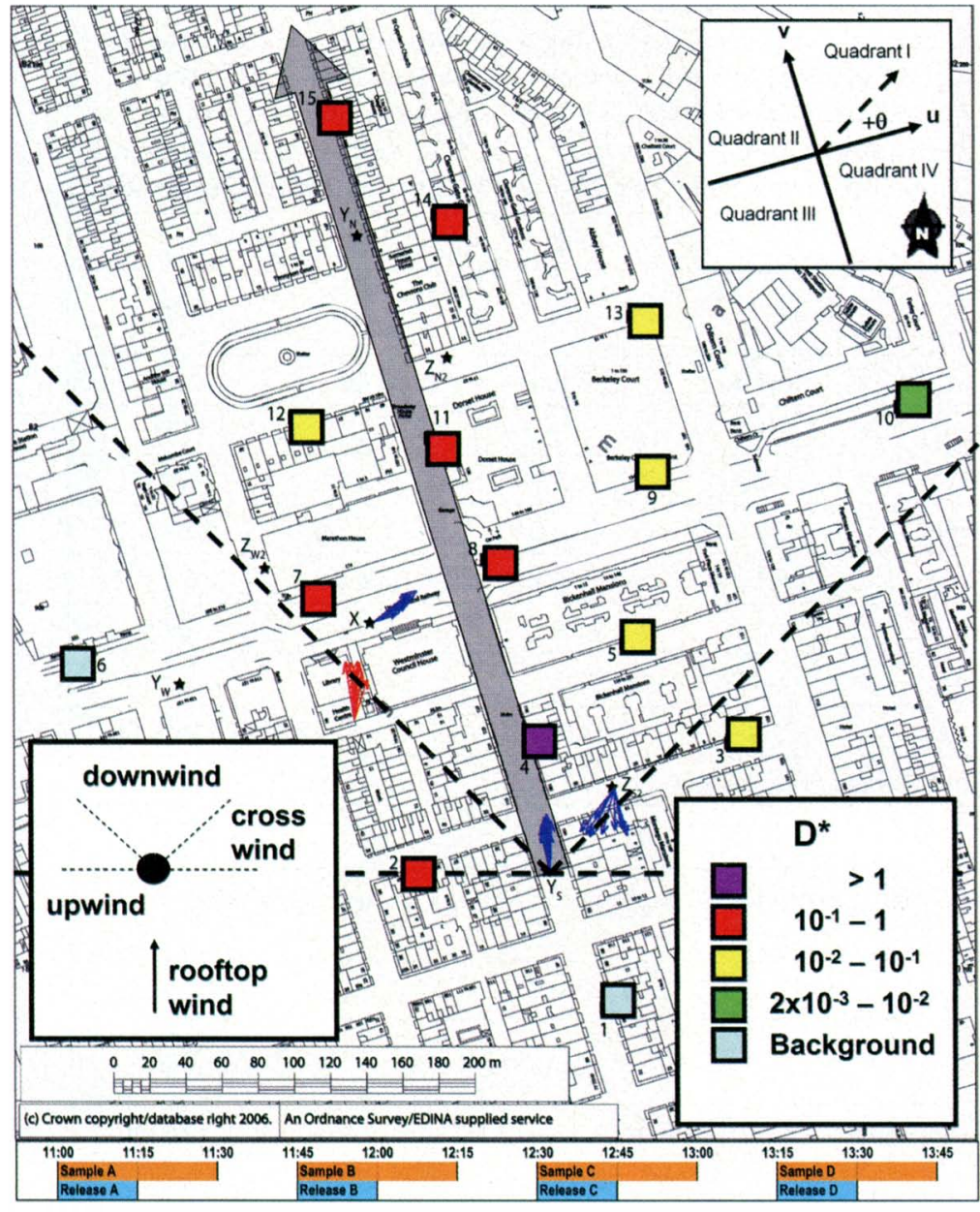

Fig. 4. Summary of flow and dispersion conditions on tracer day I. Colors are the $D^{*}$ [see Eq. (3)] values summed over the four releases at site $Y$ on tracer day I (see key for values) for the sample sites I-15. Ultrasonic anemometer data are shown as the 10 mean wind vectors over the sampling period II00-1345 UTC (hence, each individual vector is a mean over $16.5 \mathrm{~min}$ ). The flow vectors are blue at street level (sites $X, Y$, and Z; see also Fig. I) and red on rooftop (wind direction was $-86^{\circ}$ $\pm 48^{\circ}$ ). For clarity, intersection and tower-top ultrasonic anemometer data are omitted. The release and sampling schedule is marked along the bottom (UTC). Background level was $D^{*}=$ $2 \times 10^{-3}$. For analysis, the site is split into four areas [as defined in the (bottom left) inset schematic]: upwind for sites $\pm 90^{\circ}-180^{\circ}$ with respect to the mean above-roof wind direction; crosswind for $\pm 45^{\circ}-90^{\circ}$; downwind receptors are less than $\pm 45^{\circ}$; and channeling is defined as a subset of the downwind sites along Gloucester Place (which is near parallel to the mean above-roof wind direction). Channeled flow is indicated by a gray arrow along Gloucester Place. The base map is an Ordinance Survey/EDINA supplied service (๑) crown copyright/ database right 2008).

$$
C^{*}=\frac{C U_{H} H^{2}}{Q} .
$$

The paired receptors were deployed on tracer day 4 for the time-resolved experiment in which samples were taken frequently enough for the evolution of concentration to be analyzed. The synoptic situation was nonfrontal, with westerly winds (mean wind direction, $\theta=+19^{\circ}$ at rooftop; see Table 2), and hence release sites to the west were chosen, $\mathrm{Y}_{\mathrm{w}}$ and $\mathrm{Z}_{\mathrm{W}}$ (Fig. 1). Results from two sets of paired receptors are shown in Fig. 5 for the tracer release from site Y. The sites close to the site $Y$ source (7 and 16) experi-

FIG. 5. Time-evolving nondimensional concentration [C*, see Eq. (2)] at two paired sites, $7 / 16$ and 9/17 (at distances 81167 and $2721260 \mathrm{~m}$ ), from the tracer released at $Y_{w}$ on tracer day 4 from 1200 UTC onward. Each point represents a $2.5-\mathrm{min}$ sample taken every three $\min$ [(top) timeline: the orange A-I are samples and the blue is the $15-\mathrm{min}$ tracer release]. The dashed line shows the level of nondimensional background concentration $\left(5 \times 10^{-4}\right)$. 


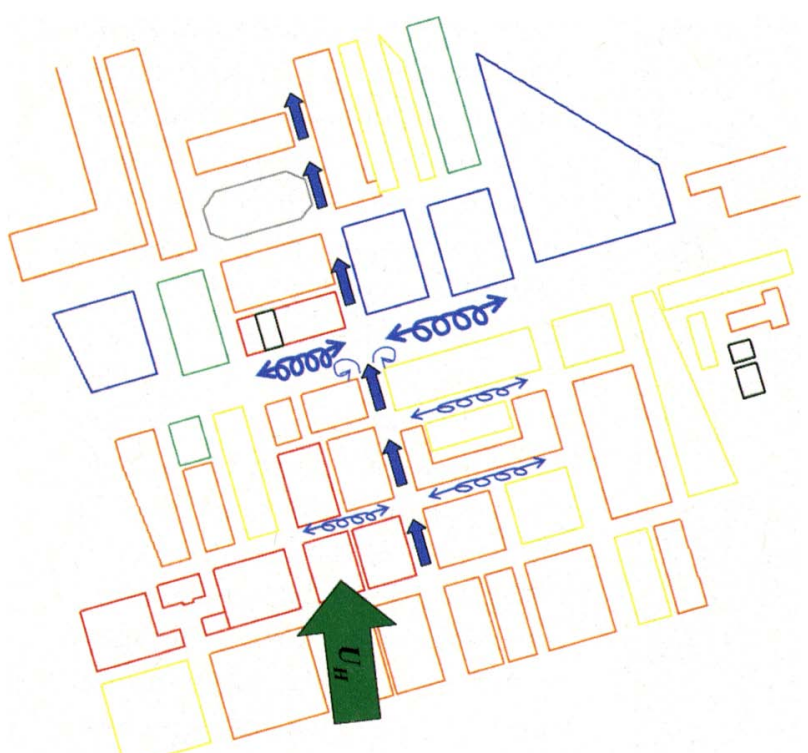

enced an order of magnitude greater concentration than those farther from the Y source ( 9 and 17) in all but the second sample (minutes 3-6) when site 7 experienced somewhat low concentrations. During minutes 3-6, the ultrasonic anemometer data at site $\mathrm{Y}$ showed that the local flow turned to $-83^{\circ}$, which was anomalous to the $-2^{\circ}$ mean for the whole 30 -min period. This local temporal fluctuation was thus consistent with the reduced concentrations seen at site 7 in the second sample. In fact, results at site 7 (receptor in the pair closest to the $Y$ source) showed considerable variability, sometimes an order of magnitude, relative to site 16 and also in time from sample to sample. Farther from the Y source (at sites 9 and 17), there was much more agreement within the pair. This was expected. At farther range the plume of material was presumably well mixed within the street canyon; however, at very short range, the tracer was unlikely to be well mixed across the street canyon. Thus, the near-source sites (sites 7 and 16) were far enough apart, relative to their distance from the $Y$ source, such that small changes in wind direction near $Y$ led to the main mass of tracer passing over one receptor site and not the other.

A decrease of tracer concentration to background levels occurred in the eighth sample (21-23.5 min) at the pair farthest (sites 9 and 17) from the Y source; this was 6-8.5 min after the release ceased. However, in this case, the levels of concentration at the nearsource sites (sites 7 and 16) decreased by more than two orders of magnitude but did not quite decay to background concentrations within the 30 -min sampling period, an observation that will have important consequences for emergency planning. However, this
Fig. 6. Schematic for flow on tracer day I (based on the background shown in "Effects of the above-roof flow and street network layout on in-street flow"). Some key flow features have been shown to aid qualitative analysis of Fig. 4. The large straight blue arrows represent channeling flow in uninterrupted street canyons, such as Gloucester Place. The curly arrows show the wake recirculations expected in canyons perpendicular to the mean above-roof wind. These arrows have two heads, showing that mean flow in the direction perpendicular (or nearly so) to the above-roof wind is weak and thus can transport material in either direction along the street canyon. Intersection flow is dominated by the channeling flow, with horizontal wake recirculations shown by arrows. The underlying map shows the wind tunnel model for buildings in the DAPPLE area; building heights are grouped and color-coded in meters at full scale as $10-14$ red; $15-19$ orange; $20-24$ yellow; 25-29 green; 30-34 blue; and 50-65 black.

result will probably need to be repeated before firm conclusions can be taken forward.

Dosage experiments were carried out on tracer days 1-3. In these experiments, there was a short-duration release of a finite amount of material, whereas sampling continued for a long enough period to capture the passage of the tracer cloud. Thus, dosage is the total exposure at one site, equal to the concentration integrated over the sample time $\left(\mathrm{kg} \mathrm{m}^{-3} \mathrm{~s}\right)$. Accordingly, nondimensional dosage is given by

$$
D^{*}=\frac{D U_{H} H^{2}}{M},
$$

where $M$ is the total mass of material released (kg; equal to the release rate integrated over the release duration).

On tracer day 1, a frontal synoptic system had moved through from west to east the previous night and southerly winds predominated. The 15 -min mean rooftop wind direction varied between $60^{\circ}$ and $100^{\circ}$ during the experiments, which gave mostly channeling flow northward along Gloucester Place. The dosages for tracer day 1 at site $Y$ were consistent with dispersion controlled by the flow features described in the "Effects of the above-roof flow and street network layout on in-street flow" section. There was strong channeling flow from the south along Gloucester Place that gave high values of dosages in the alongwind direction and a rather sharp decrease laterally. This channeled flow is indicated by the gray arrow in Fig. 4. The figure also shows areas that are defined here as downwind, crosswind, and upwind. There was no upwind dosage on this occasion as a result of the strong and persistent channeling effect northward 


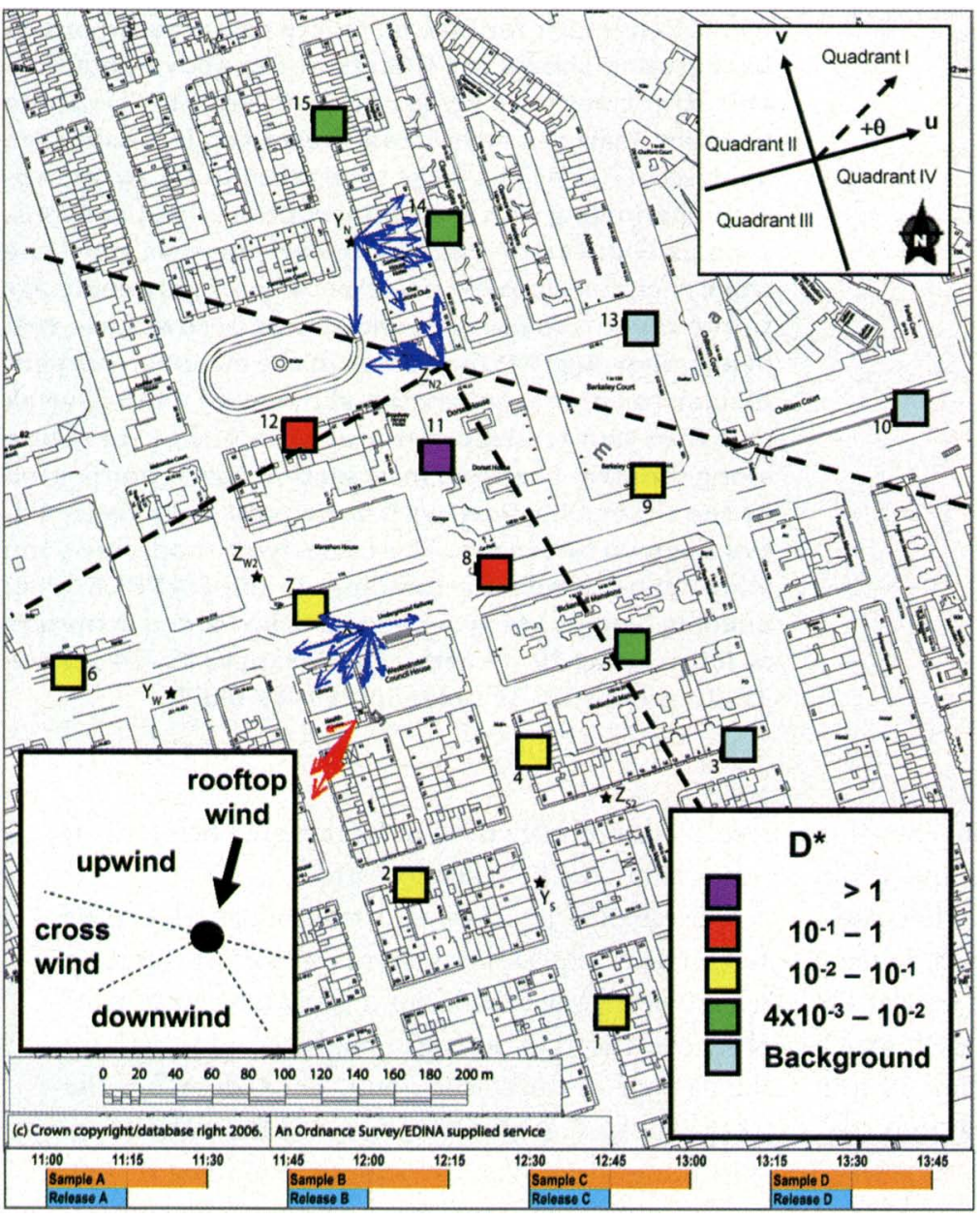

Fıg. 7. Same as Fig. 4, but for tracer day 2 at site $Z$ and colors are values at site $Z$ on tracer day 2 .

along Gloucester Place. The qualitative in-street flow characteristics are summarized in Fig. 6 in the form of a schematic to aid the interpretation of the dosage data in Fig. 4.

On tracer day 2, there was high mean-sea-level atmospheric pressure (1020 hPa at local noon) with weak winds; the 15-min mean rooftop winds were from the northeast. The wind vectors and the dosages from the release at site $\mathrm{Z}$ on tracer day 2 are shown in Fig. 7. This figure contrasts with Fig. 4, because on tracer day 2 the flow was oblique to the street network; hence, downstream receptors did not experience a narrow region of intense dosages-like on tracer day 1 -because there was no strongly channeled flow along a major road. Instead, the tracer more easily spread laterally as it was transported through the street network. In addition, the release shown was from site $Z$, a side street, in which the tracer was expected to experience extensive local in-canyon mixing before reaching other streets. Indeed, the local winds (the blue vectors at site $\mathrm{Z}$ ) show evidence of a helical structure: a canyon vortex plus downstreet transport (see "Effects of the above-roof flow and street network layout on in-street flow"). Note also the above-background dosages at upwind sites: sites 14 and 15 (up to $162 \mathrm{~m}$ from the source).

All the dosage data were pooled to show the variation of nondimensional dosage against nondimensional straight-line distance from the source (Fig. 8). The results showed a large variability but with a robust upper limit. At the farthest distances from the source, the concentration values were recorded near this upper limit only in the downwind sector. However, at short range, concentration values nearer to the upper limit were recorded for all sectors. Of the 83 values in the upwind sector, only 6 exceeded background levels farther than $6 \mathrm{H}$ from the source and no values above background were observed beyond $8 \mathrm{H}$. High tracer concentrations within an inner radius from the source of up to around $130-173 \mathrm{~m}$ $(6-8 H)$ were consequently observed regardless of the mean above-roof wind direction. The paths from the source to these elevated dosages did not cross more than two intersections; thus, we might find that a 2-block radius is a useful measure for the area of substantial contamination (at least in this area of central London).

Beyond the inner radius of contamination, there is a clear stratification of the data (Fig. 8): most of the downwind data clustered together nearer to the upper limit of the data and $97 \%$ of the downwind samples experienced above-background dosages. The upper limit of the data is constrained by cases of flow channeled from site Y northward along Gloucester Place on tracer day 1 . The decay of the maximum downstream contamination with distance is consistent with an inverse square relationship as deduced by Neophytou and Britter (2004) and confirmed by extensive wind tunnel data for a range of wind directions (Robins 2008). This upper bound can be approximated by

$$
D^{*}=12(R / H)^{-2},
$$


and this fit is shown in Fig. 8 to be equally applicable to the upper bound of field data. Hanna et al. (2007) have shown that a similar decay law applied to the dispersion data from the Oklahoma City and Manhattan experiments.

SUMMARY. A successful full-scale tracer dispersion campaign was undertaken in central London during the summer of 2007, continuing the series that began in 2004. In this article, we demonstrated the synthesis that DAPPLE can bring by the incorporation of flow features-such as channeling and corner vortices-into the tracer data analysis and reviewed results from the analysis of data from this campaign. This clearly justifies the experimental design, which aimed to allow successful sampling of much of the spatial variability in near-field urban dispersion under a range of background wind speeds and directions.

Two sets of long-term reference measurements were taken to generate a climatology of the winds at the site-in particular, the relationship between mean rooftop $(18 \mathrm{~m})$ and tower-top $(190 \mathrm{~m})$ winds. An important conclusion was that for analysis of tracer transport, the local flow in the street network was better represented by the mean wind at rooftop than tower top. However, the associated wind tunnel work was most readily characterized in terms of the "free stream" wind speed, so it was therefore important to understand the relationships between the two reference winds. A result of the continuing analysis was finding a ratio of 4.1 between the $15-\mathrm{min}$ mean wind speeds at rooftop and tower top in nearneutral conditions. This ratio is useful in assigning the same reference flow in nondimensionalized data in both wind tunnel and full-scale fieldwork. Here, the rooftop wind speed has been used as the reference with which to nondimensionalize the dosage data for comparison with models and other tracer release experiments.

Each field experiment is simply a single realization from the ensemble of possible outcomes, given the boundary conditions. At best, two or three experiments might be undertaken with very similar boundary conditions. In the wind tunnel, however, 100 realizations have been found necessary to determine reliably the statistical properties of dispersion behavior (Robins 2008). Hence, the wind tunnel is the key tool that can provide a full analysis of variability, but this too has its limitations. For example, at lower

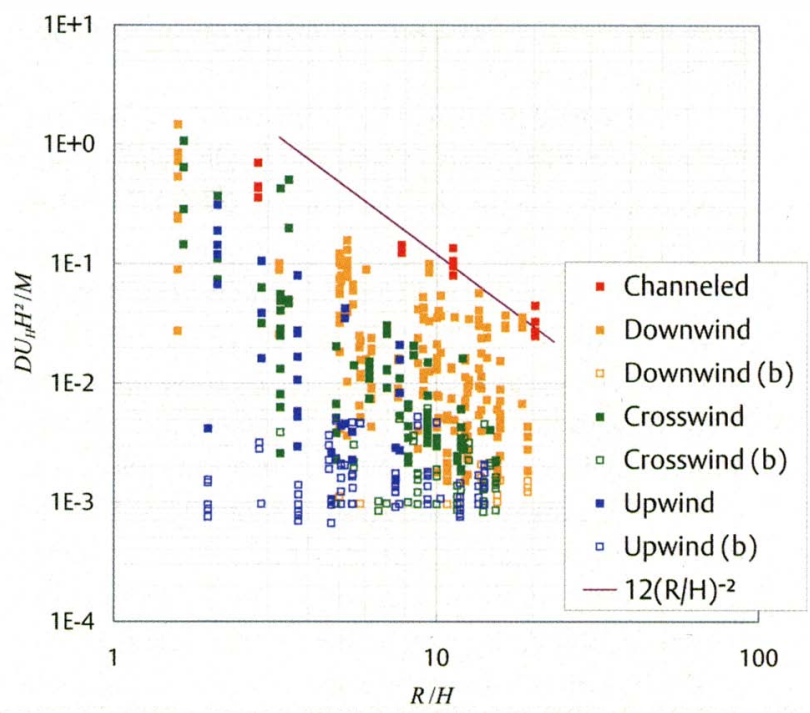

Fig. 8. Pooled results from all summer 2007 dosage experiments (tracer days I-3); 432 dosage values were analyzed. On the $y$ axis is the $D^{*}$ [see Eq. (3)]. On the $x$ axis is the nondimensional distance: the straight-line distance $R$ (i.e., not the street network route) nondimensionalized by $H$. The purple line is an empirical upper-bound fit derived from the wind tunnel work (Robins 2008), whereby the nondimensional dosage decreases with the inverse square of distance from source: $D^{*}=12(R / H)^{-2}$; see also Neophytou and Britter (2004) for further details on this relationship. The receptor dosages are coded in four groups (see inset): upwind for sites $\pm 90^{\circ}-180^{\circ}$ with respect to the mean rooftop wind direction; crosswind for $\pm 45^{\circ}-90^{\circ}$; downwind receptors are within $45^{\circ}$; and channeled sites that are a subset of the downwind sites for which the wind was near parallel to a major road on which there was a release (e.g., the case on tracer day I, see Fig. 4). The nondimensional background dosage varied from $7 \times 10^{-4}$ to $5 \times 10^{-3}$ (this range was due to the variation in mean above-roof wind speeds on different tracer days and release rates for different experiments), and colored boxes at background levels are not shaded (these empty squares are marked " $b$ " in the legend).

wind speeds, traffic-produced turbulence $\left(\mathrm{TPT}^{2}\right.$; Di Sabatino et al. 2003; Kastner-Klein et al. 2003) probably becomes important but was not included in the wind tunnel modeling. Further work is in progress to investigate such issues using the advanced large-eddy simulation model, FLUIDITY (Pain 2000; Wang et al. 2005), which includes the simulation of vehicles moving through the study area and the additional turbulence and pollutant dispersion that they induce. The key point is that all of these research techniques need to be used in a complementary way

${ }^{2}$ TPT will be analyzed by comparing in-street turbulence for different above-roof mean wind speeds-TPT is expected to contribute a higher fraction of in-street turbulence during low wind speeds-and compared with traffic flow data. 
to reach an adequate understanding of the flow and dispersion processes.

The decay of the maximum downstream contamination with distance in these full-scale experiments was consistent with the inverse square relationship. Channeling flow was observed at site $\mathrm{Y}$ on tracer day 1 , which explained the extremely high dosages that extended northward along Gloucester Place (indeed, these were the data that formed the upper limit of dosage as a function of distance from the source in Fig. 8). One of the key questions addressed by DAPPLE was whether there are simple dispersion guidelines that can be reliably applied in emergency situations. From the work summarized in this article, we can conclude that regardless of the mean aboveroof wind direction i) the most contaminated areas were within one block of the source in all directions and ii) above-background dosages are possible up to around $6-8 H$ in any direction (where $H$ is mean building height). Beyond this distance, the greatest dosages were in the downwind sector following the inverse square decay relationship and particularly at sites where there was an uninterrupted path from source to receptor along a street that was parallel to the mean above-roof flow.

Simple dispersion guidelines are essential and need careful development in their own right, separate from questions concerning their application, such as when or whether to shelter or evacuate to control exposure. Such integrated analysis clearly requires an interdisciplinary approach and is work that is continuing within the DAPPLE consortium and elsewhere in the world.

ACKNOWLEDGMENTS. We thank the U.K. government's Home Office for project funding; Transport for London for essential help with installing equipment on site; British Telecom, Eiko Nemitz, and Sue Grimmond for the equipment sited atop the BT tower; Tom Lawton for data server support; Lynette Clapp and Mike Stroud for maintenance of the rooftop reference site; Helen ApSimon, Roy Colvile, and Avi Lacser for useful comments on a manuscript draft; Hongbin Wang for campaign support; and Steve Neville for support from Westminster City Council.

We thank all the extra personnel involved in the 2007 full-scale tracer experiments: Alex Archibald, Iakovos Barmpadimos, Libby Barnes, Andrew Barrett, Steven Barrett, Mathew Bliss, Alex Brand, Michelle Cain, Nicky Chalmers, Laura Davies, Tyrone Dunbar, Ricardo Fonseca, Paulo Giambini, Paul Hamer, James Hamilton, Kirsty Hanley, Ben Harvey, Paul Hayden, Steve Henshaw, Nicky Howe, Katie Izzard, Paul Kamis, Jon Kelvin, Alan
Knights, Prashant Kumar, Payal Mehta, Richard Mohan, Keri Nicoll, Alex Nicolson, Alex Nimusiima, Henry Odbert, Anil Padhra, Frauke Pascheke, Dimitrios Pavlidis, Cristina Perez, Max Perrome, Matt Rigby, Alison Rudd, Isla Simpson, Victoria Sinclair, Helen Smethurst, Nathan Sparks, Mike Stroud, Roisin Walsh, Jonathan Wilkinson, Emma Yates, and Duick Young.

\section{REFERENCES}

Allwine, K. J., J H. Shinn, G E. Streit, K. L. Clawson, and M. Brown, 2002: Overview of URBAN 2000: A multiscale field study of dispersion through an urban environment. Bull. Amer. Meteor. Soc., 83, 521-536.

—, M. J. Leach, L. W. Stockham, J. S. Shinn, R. P. Hosker, J. F. Bowers, and J. C. Pace, 2004: Overview of Joint Urban 2003-An atmospheric dispersion study in Oklahoma City. Preprints, Symp. on Planning, Nowcasting, and Forecasting in the Urban Zone, Seattle, WA, Amer. Meteor. Soc., J7.1. [Available online at http://ams.confex.com/ams/84annual/ techprogram/paper_74349.htm.]

Arnold, S., and Coauthors, 2004: Dispersion of air pollution and penetration into the local environment, DAPPLE. Sci. Total Environ., 332, 139-153.

Barlow, J. F., A. Dobre, R. J. Smalley, S. J. Arnold, A. S. Tomlin, S. E. Belcher, 2009: Referencing of streetlevel flows measured during the DAPPLE 2004 campaign. Atmos. Environ., in press.

Bassford, M. R., P. G. Simmonds, and G. Nickless, 1998: An automated system for near real-time monitoring of trace atmospheric halocarbons. Anal. Chem., 70, 958-965.

Belcher, S. E., 2005: Mixing and transport in urban areas. Philos. Trans. Roy. Soc. London, 363, 2947-2963.

Britter, R. E., S. Di Sabatino, F. Caton, K. M. Cooke, P. G. Simmonds, and G. Nickless, 2002: Results from three field tracer experiments on the neighbourhood scale in the city of Birmingham UK. Water Air Soil Pollution: Focus, 2, 79-90, doi:10.1023/A:1021306612036.

Colvile, R. N., S. Kaur, R. Britter, A. Robins, M. C. Bell, D. Shallcross, and S. E. Belcher, 2004: Sustainable development of urban transport systems and human exposure to air pollution. Sci. Total Environ., 334-335, 481-487.

Dietz, R. N., 1986: Perflorocarbon tracer technology. Regional and Long-Range Transport of Air Pollution, S. Sandroni, Ed., Elsevier, 215-247.

Di Sabatino, S., P. Kastner-Klein, R. Berkowicz, R. E. Britter, and E. Fedorovich, 2003: The modeling of turbulence from traffic in urban dispersion modelsPart I: Theoretical considerations. Environ. Fluid Mech., 3, 129-143. 
Dobre, A., S. J. Arnold, R. J. Smalley, J. W. D. Boddy, J. F. Barlow, A. S. Tomlin, and S. E. Belcher, 2005: Flow field measurements in the proximity of an urban intersection in London, UK. Atmos. Environ., 39, 4647-4657.

Doran, J. C., J. D. Fast, and J. Horel, 2002: The VTMX 2000 Campaign. Bull. Amer. Meteor. Soc., 83, 537-551.

D'Ottavio, T. W., R. W. Goodrich, and R. N. Dietz, 1986: Perfluorocarbon measurement using an automated dual-trap analyzer. Environ. Sci. Technol., 20, 100-104.

Hanna, S., J. White, and Y. Zhou, 2007: Observed winds, turbulence, and dispersion in built-up downtown areas of Oklahoma City and Manhattan. Bound.Layer Meteor., 125, 441-468.

Kaimal, J. C., and J. J. Finnigan, 1994: Atmospheric Boundary Layer Flows: Their Structure and Measurement. Oxford University Press, 289 pp.

Kastner-Klein, P., E. Fedorovich, M. Ketzel, R. Berkowicz, and R. Britter, 2003: The modeling of turbulence from traffic in urban dispersion models-Part II: Evaluation against laboratory and full-scale concentration measurements in street canyons. Environ. Fluid Mech., 3, 145-172.

Klein, P., and J. V. Clark, 2007: Flow variability in a North American downtown street canyon. J. Appl. Meteor. Climatol., 46, 851-877.

Lagomarsino, R. L., 1996: An improved gas chromatographic method for the determination of perfluorocarbon tracers in the atmosphere. J. Chromatogr. Sci., 34, 405-412.

Lovelock, J. E., and G. J. Ferber, 1982: Exotic tracers for atmospheric studies. Atmos. Environ., 16, 1467-1471.

Martin, D., C. S. Price, I. R. White, G. Nickless, A. Dobre, and D. E. Shallcross, 2008: A study of pollutant concentration variability in an urban street under low wind speeds. Atmos. Sci. Lett., 9, 147-152.

Neophytou, M. K., and R. E. Britter, 2004: A simple correlation for pollution dispersion prediction in urban areas. DAPPLE Note Cambridge, 17 pp. [Available online at www.dapple.org.uk/downloads.]

Pain, C. C., 2000: Brief description and capabilities of the General Purpose CFD Code: FLUIDITY. Imperial College of Science, Technology and Medicine, Internal Rep.

Robins, A., 2008: EnFlo ground level concentration data and the inverse square decay law. DAPPLE-EnFlo 06v2 Note, 7 pp. [Available online at www.dapple. org.uk/downloads.html.]

- , and $\mathrm{H}$. Cheng, 2003: Initial dispersion experiments in the EnFlo wind tunnel. DAPPLE-EnFlo 01 Note, $6 \mathrm{pp}$. [Available online at www.dapple.org. uk/downloads.html.]

- E. Savory, A. Scaperdas, and D. Grigoriadis, 2002: Spatial variability and source-receptor relations at a street intersection. Water Air Soil Pollut., 2, 381-393.

— H. Heng, P. Hayden, and T. Lawton, 2004: Flow Visualization Studies-I. DAPPLE-EnFlo 04 Note, 8 pp. [Available online at www.dapple.org.uk/ downloads.html.]

Rotach, M. W., S. E. Gryning, E. Batchvarova, A. Christen, R. Vogt, 2004: Pollutant dispersion close to an urban surface - the BUBBLE tracer experiment. Meteor. Atmos. Phys., 87, 39-58.

Roth, M., 2000: Review of atmospheric turbulence over cities. Quart. J. Roy. Meteor. Soc., 126, 941-990.

Shallcross, D. E., and Coauthors, 2009: Short-range urban dispersion experiments using fixed and moving sources. Atmos. Sci. Lett., doi:10.1002/asl.211, in press.

Simmons, P. D., B. R. Greally, S. Olivier, G. Nickless, K. M. Cooke, and R. N. Dietz, 2002: The background atmospheric concentrations of cyclic perfluorocarbon tracers determined by negative ion-chemical mass spectrometry. Atmos. Environ., 36, 2147-2156.

Solomon, S., and Coauthors, 2007: Technical summary. Climate Change 2007: The Physical Science Basis, S. Solomon et al., Eds., Cambridge University Press, 19-92.

Tsai, W. T., H. P. Chen, and W. Y. Hsien, 2002: A review of uses, environmental hazards and recovery/recycle technologies of perfluorocarbons (PFCs) emissions from the semiconductor manufacturing processes. J. Loss Prev. Process Ind., 15, 65-75.

Wang, H., R. Colvile, E. Aristodemou, C. Pain, 2005: Modelling the causes of vehicle exhaust exposure microepisodes. proc. 10th Int. Conf. on Harmonisation within Atmospheric Dispersion Modelling for Regulatory Purposes, Sissi, Crete, Greece, EURASAP, 128-133. [Available online at http://harmo.org/ conferences/Proceedings/_Crete/publishedSections/ p128.pdf.]

Wilczak, J. M., S. P. Oncley, and S. A. Stage, 2001: Sonic anemometer tilt correction algorithms. Bound.-Layer Meteor., 99, 127-150. 


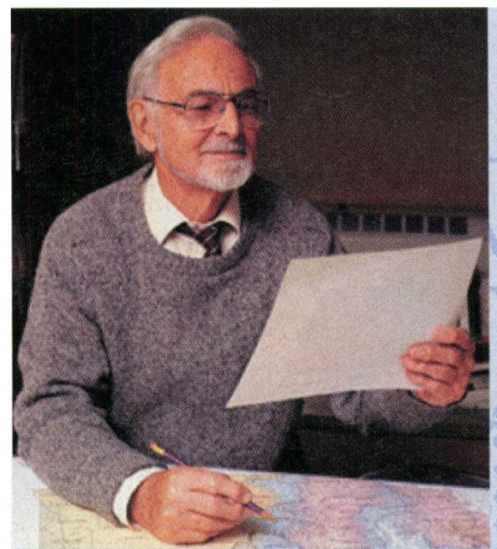

\section{A Half Century of Progress in Meteorology: A Tribute to Richard Reed}

\section{edited by Richard H. Johnson and Robert A. Houze Jr.}

with selections by: Lance F. Bosart Robert W. Burpee Anthony Hollingsworth James R. Holton Brian J. Hoskins Richard S. Lindzen John S. Perry Erik A. Rasmussen Adrian Simmons Pedro Viterbo

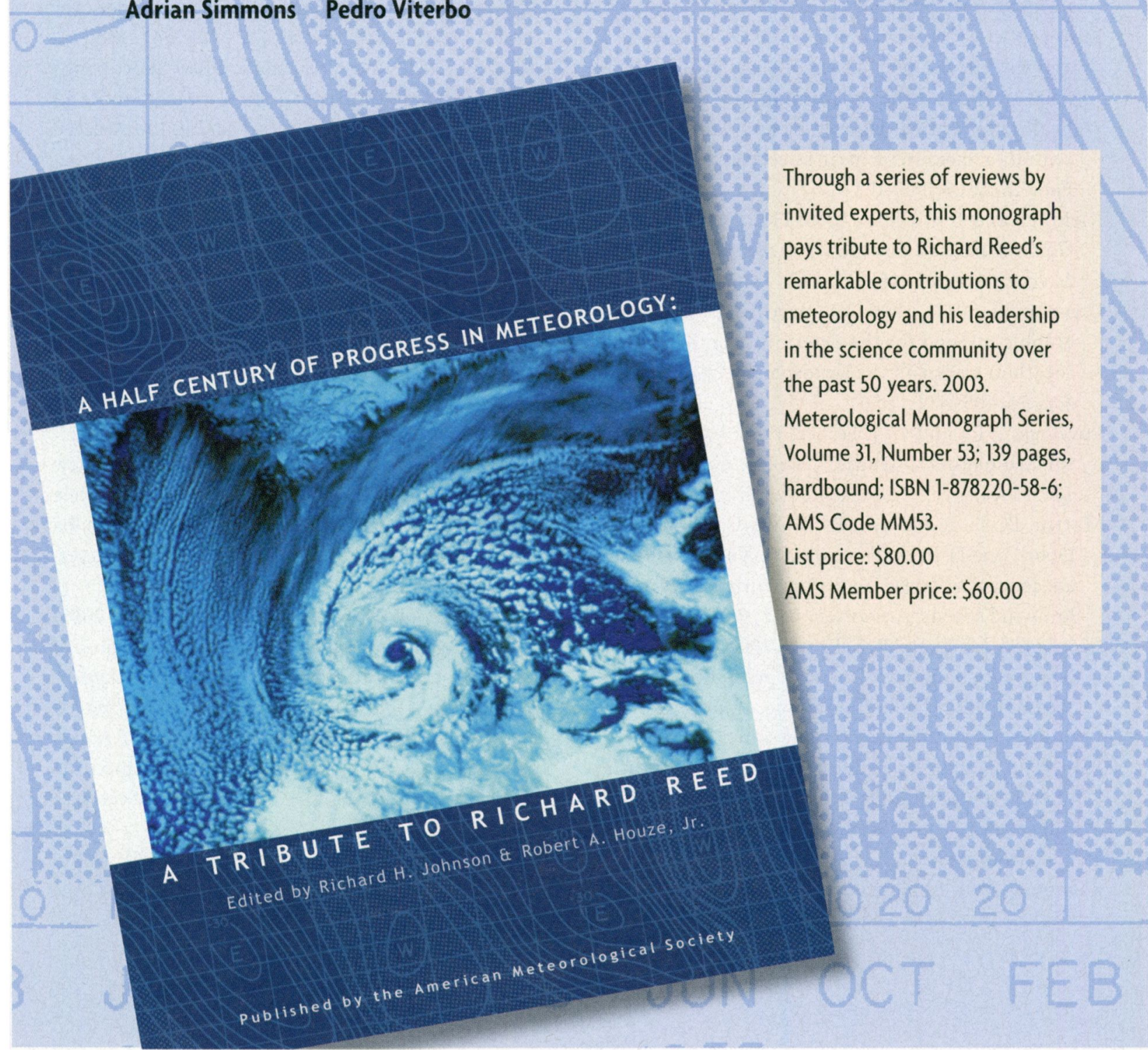

